Revista

\title{
Multi-Ensayos
}

Vol. 7, núm. 13

ISSN: 2412-3285

https://multiensayos.unan.edu.ni

DOI: https://doi.org/10.5377/multiensayos.v7i13.10747

\section{Educación superior: prácticas virtuales tradicionalistas y la ausencia del discurso reflexivo}

\section{Higher education: traditional online practices and the absence of reflective discourse}

Omar Pineda Luna

Recibido: 14 de octubre de 2020. Aceptado: 09 de noviembre de 2020

\section{RESUMEN}

El presente ensayo está encaminado a reflexionar sobre el papel del profesor y profesora ante la contingencia sanitaria derivada por el coronavirus SARS-CoV-2. Principalmente, problematizar el escenario educativo durante la pandemia y las prácticas virtuales educativas, así como la postura del estudiante ante los cambios repentinos que significó trasladar lo presencial a lo virtual. Finalmente, se expone la necesidad de un discurso crítico del papel que desempeña la escuela como espacio de reflexión y análisis de los problemas sociales, tales son: los casos de violencia contra la mujer en los últimos meses.

Palabras clave: educación; prácticas educativas; reflexión; violencia; coronavirus.

\begin{abstract}
The present essay is aimed at reflecting on the role of the teacher facing the health contingency derived from the SARS-Co-2 coronavirus. Education during the pandemic and virtual / online educational measures are discussed, as well as the position of the student in the context of the sudden shift to online educational provision. The need for a critical discourse on the role of the school as a place for reflection of social problems is underlined. Such problems include the cases of violence against women in recent months.
\end{abstract}

Keywords: education; educational practices; reflection; violence; coronavirus.

1 Escuela Normal Superior de Tehuacán. Correo electrónico: omarines10@gmail.com (c) 2021 Revista Multi-Ensayos. 


\section{INTRODUCCIÓN}

Además de las secuelas sanitarias, económicas, políticas y sociales que la pandemia está dejando a nivel mundial, se debe agregar las consecuencias reflejadas en el sector educativo, específicamente en las escuelas públicas de México. A partir de la declaratoria de emergencia sanitaria pronunciada por el Gobierno Federal y el secretario de Educación Pública, las escuelas en México se vieron obligadas al diseño de actividades en modo virtual y a distancia. Algunas instituciones se alarmaron tanto, que actuaron de manera apresurada sin saber que, en algunos casos, el profesorado no estaba preparado para las clases "online" y tampoco los estudiantes. Si bien debe ser una competencia del docente-dicente del siglo XXI, la realidad es diversa, pues depende, en gran medida, de las zonas geográficas, capacitaciones, insumos, recursos públicos o privados, entre otras cosas. Lo anterior, para cumplir cabalmente con las habilidades tecnológicas que la educación virtual exige. No obstante, cabe hacer algunas aclaraciones al respecto:

Según estadísticas del INEGI del 2019, sólo el $56.4 \%$ de los hogares tiene acceso a internet y el $44.3 \%$ tiene una computadora por hogar. Es decir, en una familia donde tres de sus integrantes asisten a la escuela tendrán que usar, en un semejante horario escolar, un mismo ordenador, esto en el mejor de los casos, porque en otro escenario deberán asistir a un establecimiento a pagar por el uso de computadoras e internet. Ello refleja que no todos los estudiantes podrán dar continuidad al ciclo escolar en línea al no tener los insumos necesarios para enfrentar las crisis.

Pero la pandemia también expuso, lastimosamente, otros atisbos del sector educativo público de México, que ya existían, pero ahora son más visibles y subyacen en las prácticas educativas de profesores y profesoras, es decir, qué tanto se modificaron o sólo hubo un trasladó de lo presencial a lo virtual y siguieron repitiendo técnicas y metodologías tradicionalistas en la virtualidad. Por otra parte, cuál fue la recepción de los estudiantes, sabemos que en la educación actual existe una responsabilidad compartida entre profesorado y estudiantes para construir el aprendizaje, en ese sentido, qué carencias por parte de los dicentes fueron exhibidas.

Finalmente, una llamada de alerta en las escuelas superiores del país, sobre todo, por la ausencia de los discursos educativos de profesoras y profesores de temas relacionados con problemas actuales, tal es el caso de la violencia hacia la mujer, ¿Qué lo político no es educativo? ¿No es la escuela un espacio de reflexión y debate de las problemáticas sociales actuales? Pareciera que la educación se encuentra en una burbuja donde todo es dulcificado, en ocasiones afirmamos que la política no debe ser un tema escolar, de esta manera nos encerramos en el aula, en el método, en la estrategia. Así, la escuela se aleja de la realidad y se aísla de los problemas sociales, por ello, es necesario recuperar los acontecimientos de la vida real para conversarlos, reflexionarlos y debatirlos en nuestros discursos diarios al momento de impartir un curso.

\section{¿Actualizarse en tecnología significa enseñar mejor?}

¿Cambió la práctica escolar presencial en lo virtual? ¿Se siguen repitiendo patrones de la educación tradicional, ahora de manera digital? ¿El regreso a las aulas debería continuar con las mismas prácticas hasta antes del 23 de marzo del 2020? Si bien una de las ventajas que la pandemia cultivo en los profesores 
y estudiantes fue la obligación por desarrollar habilidades tecnológicas en el campo educativo. No obstante, estas nuevas formas tienen su propia dinámica y aplicación, es por ello que desde que inició del presente ciclo escolar los planteamientos anteriores están presentes en el quehacer educativo diario, ahora en la virtualidad, por eso es importante responder y exponer algunas razones retomando lo que varios estudiantes conversan entre ellos y con sus profesores.

Lo anterior, invita a reflexionar sobre la profesión docente, sobre todo, exponiendo que, si un profesor del siglo $\mathrm{XV}^{1}$ despertara a inicios del siglo XXI, su práctica seguirá siendo la misma, es decir, el uso de un gis/ plumón; una pizarra/pizarrón y un contenido/libros de textos. Si se compara con otras profesiones, como la del médico, éste no podría operar, dados los avances tecnológicos desarrollados durante cinco siglos. Lo que demuestra como el proceso de enseñanza ha quedado atávicamente rezagado.

Actualmente se pueden extrapolar dichos ejemplos, principalmente por la dinámica presente en el ciclo escolar, que derivado de la contingencia sanitaria obligó al profesorado a entrar a la "nueva" tendencia educativa, al respecto, es importante problematizar algunas cuestiones educativas docentes en este escenario de virtualidad. Es de llamar la atención las prácticas escolares que se repiten dentro del ámbito docente, pero ahora de manea virtual. Ya de por sí en el aula eran ancestrales, reproducirlas de manera virtual parece una contradicción, en este sentido referimos, especialmente, a: el dictado, el pase de lista, la aplicación de exámenes vigilados mediante cámara y el autoritarismo educativo virtual.

Para contextualizar el primer aspecto, fue en el siglo XVIII que Carlos III propuso reformar la educación, primeramente, en todas las universidades, en un intento por centralizar y uniformar la enseñanza en sus contenidos, incluía el mandato para desparecer el dictado en las entonces cátedras universitarias (Marsiske, 2001). Es decir, desde 1755, el dictado debió desaparecer, por lo menos de la universidad. No obstante, es una técnica que sigue utilizándose, la singularidad que presenta es que ahora se dicta a la distancia de monitor a monitor, pasaron más de 260 años y, en universidades privadas y públicas en México, no se ha logrado eliminar el dictado como "método de enseñanza", tampoco los estudiantes han puesto resistencia u objeción ante estos procedimientos, en parte porque se normaliza, y por otra, para no contradecir al docente.

También persiste, el pase de lista. Hacerlo de manera presencial no tiene ningún sustento pedagógico, ahora practicarlo virtualmente parecería irrisorio, si bien el argumento es que el estudiante debe conectarse en tiempo de hora clase, esto de ninguna manera asegura que preste atención o tome apuntes, bien puede conectarse decir "presente" y dormir, acostarse, hacer tarea de otra materia, estar en redes sociales, etc. En este sentido, ya Michel Foucault, en el siglo pasado (1975), advertía de las semejanzas entre la cárcel, los centros psiquiátricos y la escuela, exponiendo que en los tres espacios existen paralelismos como: el

\footnotetext{
1 Se elige este siglo por lo que señala Torres (2017) Es durante la Edad Media Baja que las aulas adoptan un vocabulario profesional claramente construido por la iglesia, a decir de este autor em el siglo XV y en el Renacimiento es que las primeras instituciones educativas controladas por la iglesia tenían como finalidad encauzar y domesticar la indócil personalidad infantil, en especial la de las clases populares. La escuela formaba creyentes y súbditos, sirviéndose de una pedagogía que subraya el carácter dogmático del conocimiento mediante la memorización y con un profesorado también autoritario ( $p .30$ ) de ahí el origen del vocabulario en la educación, por ejemplo: Profesor, del griego, "prophetes", los profetas que transmiten las verdades por la divinidad; Maestros, del latín, "magister", maestros que son en ese periodo histórico los grades teólogos como Santo Tomás de Aquino; Cátedra, del griego "Kathédra", el sillón o trono papal y de los obispos; el espacio de la catedral; Los Textos, lo que venimos dominando como libros de texto, son los textos sagrados; La Vocación, del latín, "vocare", la llamada de Dios a determinadas personas para solicitarles que se pongan a su servicio.
} 
uso de uniformes, los horarios de comida o visita, el control del tiempo y un sistema punitivo sancionador (existe una autoridad que manda y alguien que obedece, no cumplir con las normas equivale a una sanción). A estos elementos agrega este ensayo, el pase de lista, ¿en dónde más realizan está práctica? En la cárcel, el psiquiátrico, la milicia, y, por supuesto, la escuela.

Por otra parte, existe el examen, instrumento que "mide" el aprendizaje, pero que esta mediado por el poder disciplinario, un dispositivo de vigilancia. "Consiste en coacción por el juego de la mirada, unas miradas que deben ser vistas. Lo cual requerirá además de una arquitectura especifica de observatorio para llevar un control interior, articulado y detallado" (Urraco y Nogales, 2013:159). Además, ¿qué miden los exámenes? la acción es simple, representa el ejercicio de dictar conocimiento, se lanza como especie de Frisby, los estudiantes lo recogen y los devuelven en una hoja o por correo. Esta acción se ha llevado al ámbito digital, pues en varias evaluaciones los maestros y maestras exigen al estudiante contestar un examen, hacer que prendan su cámara y vigilarlos para que no busquen en internet la respuesta o este alguien ayudándolos, por supuesto se pueden aplicar los cuestionarios que permite Google, donde se determina un tiempo límite para contestar. Sin embargo, la acción de examen sigue siendo la misma. Esta práctica, paulatinamente, está siendo sustituida por otro tipo de evaluaciones.

Por último, se observa el autoritarismo educativo virtual, esta especie de disciplina del profesor/a por imponer sus reglas mediante gritos e insultos, obligando a usar las cámaras, conectarse en horarios determinados, sin preguntar la situación familiar, emocional o económica por la que atraviesan los estudiantes, o si tienen un espacio destinado para aprender. Tal como se vio reflejando en el vídeo que se hizo viral en redes sociales, teniendo como protagonista a una maestra que gritaba para que su estudiante utilizara la cámara. O el otro caso sonado, la profesora que humilló a su alumno por no tener un lugar "digno" donde tomar clase y estar utilizando la computadora en un "cyber". La exposición ante este "panóptico digital" evidencia lo que pasa dentro de las clases, pero ahora de manera virtual. Lo anterior, es una llamada de alerta, de lo contrario únicamente existe un traslado de lo presencial a lo virtual, con idénticos arcaísmos que ya de por sí tienen las aulas. Lo mismo, pero de lejitos.

Ante este corolario, cuestionar ¿Qué está pasando? Pareciera que un sector de maestros y maestras demanda que la televisión y el uso de la tecnología no es la alternativa, no obstante, los estudiantes aseguran aprender mejor de "el profe Julio", así lo exhiben las miles de reproducciones que tiene su canal, ¿qué hace diferente en su método de enseñanza? Si el principio es el mismo: una cámara, un pizarrón y un plumón. En este sentido, preguntarse ¿qué uso incorrecto se está haciendo?

\section{Y los estudiantes ¿Qué?}

La pandemia no sólo evidenció las prácticas educativas tradicionales en lo virtual, también exhibió el desarrollo de los estudiantes quienes al principio argumentaban: "esas" no eran clases, no existía retroalimentación, las indicaciones eran desordenadas, poco precisas y, en ocasiones, hasta mal redactadas, no había respuesta ante dudas o aclaración de conceptos, en otras palabras, no encontraban un sentido didáctico o de aprendizaje significativo en las actividades que dejaban los profesores. La pregunta sería

2 Aunque para Han (2013), la idea de panóptico digital se aleja de la función de óptica perspectivista, para este autor, el exhibicionismo y el voyeurismo de las redes sociales alimenta el panóptico digital. La sociedad del control se consume allí donde su sujeto se desnuda no por coacción externa, sino por la necesidad engendrada en sí mismo. (p.87) 
¿se encuentra en las clases presenciales? Dejando a un lado los constantes señalamientos en contra del profesorado, también evidenció la naturaleza de alumnos y alumnas, necesitar que alguien les explique, condición, al parecer, del sistema educativo mexicano.

¿Qué implica el sistema explicador o el maestro explicador? Rancière (1987), tomando como evidencia el caso del Joseph Jacotot, expone sus características "El explicador es el que necesita del incapaz como tal. Explicar alguna cosa a alguien, es primero demostrarle que no puede comprenderla por sí mismo" (p.23), este acto se conoce como atontamiento. Veamos un ejemplo más claro que exhibe el mismo autor ¿qué es lo que el niño aprende mejor? Las palabras, aquellas que se apropia en el sentido de su constante uso, son aquellas que aprende sin maestro explicador. Se les hablan y se hablan alrededor de ellos. Ellos oyen y retienen, imitan y repiten, se equivocan y corrigen, tienen éxito y vuelven a comenzar por método.

Ahora bien, este niño que ha aprendido a hablar a través de su propia inteligencia y aprendido de aquellos maestros que no le explicaban la legua empieza su educación propiamente dicha. No obstante, pronto tendrá tantos maestros como materias para comprender, impartidas en cierto orden progresivo lo que resultara en el sistema explicativo, como pone en relieve Rancière, [los docentes] "dirán, es necesario explicarle cada vez mejor. Tal es la preocupación del pedagogo educado: ¿comprende el pequeño? No comprende. Yo encontraré nuevos modos para explicarle, más rigurosos en su principio, más atractivos en su forma. Y comprobaré que comprendió" (p.25).

Así, profesores y profesoras se esfuerzan por perfeccionar el método de explicación, para hacer comprender mejor, para aprender mejor a aprender. Para convertir las explicaciones en más comprensibles para aquellos que no la comprenden. El mundo divido entre "espíritus ignorantes y espíritus sabios, capaces e incapaces, inteligentes y estúpidos". De esta manera el niño adquiere una nueva "inteligencia" la de las explicaciones del maestro. Mas tarde también él podrá ser explicador.

Lo anterior, responde a por qué los estudiantes no han podido dirigir su aprendizaje de manera autónoma en estos tiempos de confinamiento, no sólo no ha podido utilizar las tecnologías de la información, sino que se han formado un sistema de dependencia de un explicador, o peor aún, como dice Iván llich (1970) "Los alumnos jamás han atribuido a sus maestros lo que han aprendido. Tanto los brillantes como los lerdos han confiado siempre en la memorización, la lectura y el ingenio para pasar sus exámenes, movidos por el garrote o por la obtención de una carrera ambicionada" (p. 42). Una explicación, ante esta situación, es que desde los niveles básicos se ha optado por un sistema explicador, por lo tanto, una modificación deberá darse, no sólo en la práctica educativa del profesor o profesora, sino desde la formación de docentes, quienes deberán asumir pasar del profesor explicador al profesor emancipador ${ }^{3}$.

\section{Programa aprende en casa: accesible, pero no deseable}

Entre todas las opciones que había para el regreso a clases, el planteamiento de transmitir los contenidos educativos vía televisión era la más viable, de acuerdo con cifras del INEGI el $92.5 \%$ de los hogares en México cuenta con televisión, dada la cobertura de este medio de comunicación, representaba la solución más asequible, sin que fuera la deseable. Ya que en el contexto de la pandemia se tiene que asegurar que los contenidos lleguen a la mayor cantidad de personas posibles. 
En este sentido, habría que debatir algunos aspectos del programa "Aprende en casa II". Al inicio desato una serie de polémicas por considerarse programas repetidos de otros países, con conductores que utilizaban ejemplos de su lugar de origen, y, por lo tanto, los niños y niñas no lograrían entender los contenidos. Se tiene presente la crítica de Miguel Ángel Rodríguez ${ }^{4}$, cuando menciona "La educación bancaria concibe solo un lado activo de los procesos de enseñanza y aprendizaje: el profesor que sabe y transmite, es él quien deposita los conocimientos, en este caso los contenidos de los programas de estudio por televisión, a las y los estudiantes, recipientes vacíos que reciben pasivamente, y durante varias horas al día, el discurso de los sabios de la aldea" (Televisión y educación Bancaria, párr 8). Sin embargo, al revisar el programa durante estos días, y haciendo el ejercicio de estar con un infante observando el programa de su grado escolar, se puede argumentar el esfuerzo de los maestros que están realizando los programas por televisión, incluso en un estudio aplicado a estudiantes de la Escuela Normal Superior de Tehuacán, exponían que, en su observación se percataron que tenía sus bondades, Así argumentaban podría funcionar, siempre y cuando existiera un acompañamiento de algún adulto, incluso había quienes afirmaban que padre e hijo estaban aprendiendo ejercicios básicos matemáticos.

Si bien en un principio fue satanizado, hoy se puede observar que los conductores auxilian como alumnos, y los profesores y profesoras pertenecen al gremio docente, se puede admirar el desempeño que están realizando, y, además, romper con los estereotipos que sólo personas con determinadas características pueden estar en televisión. Por supuesto, que la televisión no sustituye el quehacer docente, pero en estos momentos es lo que se tiene a la mano.

Hasta este punto se han expuesto algunas circunstancias que seguimos repitiendo dentro del aula, presencial y virtual, pero también existe la otra cara de la moneda, profesores y profesoras que han entrado de lleno a la dinámica virtual, capacitándose, invirtiendo y haciendo el esfuerzo para que los estudiantes aprendan de la mejor manera, utilizando las ventajas digitales. Existen otros casos donde maestros y maestras, que al saber que sus estudiantes no tienen los medios virtuales, han optado por asistir a las comunidades y visitar a sus alumnos y alumnas para tratar de guiar el conocimiento necesario, llevar y traer planeaciones, principalmente, en las periferias. Dejar claro que los esfuerzos de maestros y maestras tienen como objetivo salvaguardar la salud de la comunidad estudiantil, pero también llevar los aprendizajes por los medios posibles.

\section{Escuela y profesorado crítico-reflexivo}

En 1971, Antonio Gramsci, exponía la necesidad de la comprensión del mundo y la razón que lo trasforma, sobre todo cuando pone en relieve:

El hombre de las masas activo, tiene una actividad práctica, pero no tiene conciencia teórica clara de su actividad práctica, la cual incluye la comprensión del mundo y la razón por la que éste se trasforma. Su conciencia teórica puede verdaderamente estar históricamente en contradicción con su actividad. Uno puede casi decir que él tiene dos conciencias teóricas (o una conciencia contradictoria); una que está implícita en su actividad y qué en la realidad lo une con todos sus compañeros trabajadores en la trasformación práctica del mundo real: y otra, superficialmente explicita o verbal, que ha heredado del pasado y que ha absorbido acríticamente (p.81)

4 Para más información https://www.e-consulta.com/opinion/2020-08-05/television-y-educacion-bancaria [consultado el 29/09/2020] 
En este escenario de crisis, retoma más fuerza la idea de la politización de la escuela, en el sentido de las relaciones que se establecen dentro de la institución como las externas, con el propósito de mostrar una reflexión y postura ante la situación social del país. Actualmente, resultado de la pandemia, es probable que los estudiantes estén atravesando por una precariedad económica y laboral, pues varios de ellos trabajan para sostener sus estudios. En los niveles básicos, es preocupante que los padres y madres de familia disminuyan sus ingresos o tengan que ser despedidos, y sientan angustia porque pronto enfrentarán la escases de alimentos, renta y el pago de servicios, lo que impedirá sufragar el internet y seguir con las actividades académicas desde casa. Así, en estos momentos cumplir y dar seguimiento a los planes de estudios puede esperar un poco. Maestros y estudiantes pueden ayudar a comprender la situación actual, cómo desde la escuela se apoya a las situaciones que están por presentarse, una educación solidaria. Que entienda y atienda las necesidades reales que están porvenir, reflexione y actúe en la medida de las posibilidades de cada persona, como menciona Sebastián Plá, "Me parece que los docentes equivocamos el camino. No se trata de llevar la escuela a la casa, con la misma carga horaria y contenidos curriculares. Se trata de responder cómo la escuela ayuda a sobrellevar a niños y niñas el encierro y la pandemia en casa" (La jornada, 10 de abril de 2020: párr 5)

Por otra parte, es verdad, el profesorado atiborró a los estudiantes de tareas a través de las diferentes plataformas digitales, pero, en ese sentido, directivos, administrativos y docentes también fueron requeridos formatos y papeleo para su entrega inmediata con la finalidad de cumplir con los aprendizajes esperados de cada materia. Asimismo, el confinamiento dejo ver la parte más represiva en las autoridades públicas y dueños de instituciones privadas, una constante vigilancia y control virtual. Algunas universidades privadas pidieron estar "presentes" en las clases virtuales con la finalidad de supervisar que los maestros y maestras cumplieran con los requerimientos, tiempos y temas de acuerdo con el programa y horario, condicionando el pago en caso de no hacerlo. Ante esta panóptico, las autoridades y dueños de las universidades rendimiento ${ }^{5}$ deben dejar de vigilar a los profesores y profesoras y otorgar la libertad y confianza que merecen para que nosotros asumamos con responsabilidad nuestra labor educativa docente.

\section{La escuela ciega ante la violencia}

Uno de los últimos lugares donde aún es permitido el debate, la tolerancia, el respeto, la pluralidad de ideas y construcción de escenarios ideales es la escuela, en todos sus niveles, desde el básico hasta el superior. Aun cuando el empirismo y el positivismo continúan dominando en la mayor parte de las instituciones escolares, la educación ha resistido la conquista del poder económico, la imperecedera batalla entre el logos y la lógica como finalidad del proceso educativo; el primero en relación a la razón como principio motor y organizador del mundo, el segundo, como racionalidad que alude a la técnica, adiestra y sirve al capital, en ese sentido, como humanidad hemos fortalecido la segunda al grado de

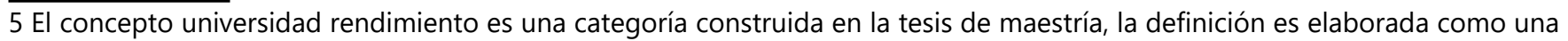
referencia a la sociedad del rendimiento de Byung Chul Han,. Es por lo que la universidad rendimiento es aquella institución de enseñanza superior pública o privada que tiene como sustento ideológico lo que indican los organismos internacionales que detentan el poder económico y que, por lo tanto, los contenidos son elegidos por los encargados de aumentar la producción a nivel mundial, como pasó con el proyecto DeSeCo que pronto se convirtió en el proceso de Bolonia. La universidad del rendimiento, como se dijo, puede ser pública o privada, son instituciones sometidas a estándares de calidad y eficiencia que deben someterse a procesos de certificación empresarial, donde, no sólo los estudiantes son sometidos al rendimiento de los proyectos, calificaciones, etc. sino también los profesores y profesoras son evaluados dependiendo del provecho académico que hayan tenido en el semestre inmediato (Pineda, 2019) 
impregnar todos los aspectos de nuestra vida con una lógica de mercado, caracterizada por un mínimo esfuerzo consiguiendo resultados medianamente aceptables. Un ejemplo sencillo de la vida estudiantil son las tareas: profesoras y profesores dentro su práctica educativa diaria solicitan investigaciones a las que asignan un valor, generalmente estandarizado, los estudiantes, por su parte, atienden a su racionalidad copiando o haciendo los requerimientos, sin saber por qué el maestro pidió ese trabajo o comprender lo que significa y mucho menos su utilidad, ya que si respondiera a éstas preguntas estaría aludiendo a su razón, sin embargo, al presentar las tareas el resultado es el mismo, obtienen el valor asignado haciendo el mínimo esfuerzo con el equivalente efecto para todos. Atienden a su lógica no a su logos.

Ante el escenario de violencia contra los mexicanos y mexicanas ¿Cuál es el papel de los educadores y educadoras respecto a la situación actual del país? ¿Qué papel han desempeñado para fortalecer o prevenir la violencia? Es desde las aulas ¿Dónde profesoras y profesores permiten o generan todo tipo de intimidación? ¿En dónde más debatir la violencia que vive el país? por qué la mayoría de los maestros y maestras no han dedicado un tiempo de su asignatura para fijar una postura hacia la violencia ejercida contra la mujer durante los últimos meses.

La respuesta puede llevar a diversos escenarios, pero el principal responde a una profunda deshumanización que ha penetrado en las aulas, desde los planes de estudio, los exámenes de rendimiento académico, las planeaciones escolares, los procesos y productos, las constantes evaluaciones estandarizadas de calidad y eficiencia para demostrar la aprobación de los procesos de certificación empresarial, etc. Todo lo anterior de manera sutil, poco perceptible para los que ejerce la profesión de enseñar y aceptan las exigencias del sistema educativo del rendimiento sin cuestionarlo, como afirma Henry Giroux (1992) "la lógica de la racionalidad tecnocrática y anclada en un discurso que encuentra principios universales de la educación que están cimentados en el ethos del instrumentalismo o del individualismo al servicio propio" (p.22)

Pero una lucha constante, ese tipo de resistencia minúscula de la que habla Walter Benjamín, es hoy un grito mundial y que, gracias a ellas, varias mujeres han decido hablar de la violencia que han sufrido en el pasado, porque pueden presentarse los discursos eufemísticos que considera el pasado como superior, fácilmente llevar a una romantización del mismo y con ello el peligro de que el presente y futuro representen una involución de la sociedad. Aunque no son suficientes, no podemos negar los avances que ha tenido la sociedad en su conjunto.

Es importante exponer las razones por las cuáles dentro del discurso educativo debe estar siempre presente la violencias sistémicas y estructurales por las que atraviesa el país, muchas veces pareciera que se llega al aula se abarcan los contenidos y se encierra en una burbuja como si el salón de clases se mantuviera situado en otra realidad, ya lo exponía Adam Schaff (1974) que el proceso de conocimiento tiene tres modelos explicativos: mecanicista, idealista-activista e interacción. Para el filósofo polaco en el primero, el sujeto es considerado como un agente contemplativo. "En consecuencia, el resultado de este proceso de conocimiento resulta ser una especie de reflejo o copia del objeto" (p.81), como el hecho de duplicar lo que está escrito en el pizarrón a la libreta de manera mecánica. El segundo, se caracteriza "por el predominio del sujeto cognoscente que percibe al objeto de conocimiento como su propia producción" (ibidem) el agente comienza a generar ideas, pensamientos. Por último, el tercer modelo explicativo, una suerte de interacción entre el primero y segundo oponiéndose a la preponderancia del objeto y del sujeto 
"el sujeto del conocimiento se produce en el marco de la práctica social de quien percibe al proceso de la realidad, $y$, en consecuencia, el conocimiento siempre es resultado de una actividad social" (ibidem).

En este escenario, resulta inevitable referirse, estrictamente, a que no hay cabida en las aulas a los problemas sociales, como es el caso de los feminicidios, cuántos de los maestros y maestras decidieron dedicar unos minutos de clase para hablar de los feminicidios de Alondra, Nayeli, Carmen y Jessica González, ésta última se iniciaba como maestra de preescolar en el estado de Michoacán. ¿A caso el tema de violencia que vive la mujer en el país no debería estar presente, por lo menos, en la reflexión del profesorado?

Por lo anterior, profesoras y profesores deben comenzar por una deconstrucción (en los términos que plantea Jacques Derrida) personal, es decir, abrir todo aquel concepto que se presenta como último y definitivo, desestabilizar el sentido común, evidenciar el carácter arbitrario de toda certeza, en este caso de lo que se entendió como masculino y femenino, no obstante, éste desmantelamiento de los hábitos enseñados en casa conlleva un proceso, primero, el admitir las prácticas que se han legitimado desde el aula y la escuela como dominio de hombres sobre mujeres, sin este primer paso, es improbable educar con perspectiva de género. Por el contrario, si desde la escuela continua en pasividad pronto se traducirá en condonar la conducta y por lo tanto perpetuarla, con ello, desde los discursos escolares reforzamos la inmolación social. Aunque es cierto que varias escuelas fijaron una postura a favor del paro del pasado 9 de marzo, en la práctica siguen promoviendo una masculinidad hegemónica o ¿Cuántas de las universidades públicas de México son presididas por una mujer? ¿Cuántas han sido rectoras? Hace no mucho se permitió ocupar el cargo de directoras o bien coordinadoras. Este es otro llamado para no caer en discursos dulcificados en la lucha por la equidad de género, bajo el argumento "les doy permiso" o "les damos el día".

\section{CONCLUSIONES}

Ante este escenario de incertidumbre pandémico, es necesario que la sociedad este consciente que la educación no es la panacea de todas las problemáticas actuales. Existe ya un linchamiento mediático hacia los profesores porque las madres y padres de familia se preguntan ¿Qué está haciendo el profesor? ¿Por qué sigue cobrando "sin hacer nada"? La contingencia sanitara esta desnudado los aspectos más insensibles de la sociedad. En este sentido, durante las últimas décadas, existe un exaltado fervor por resolver los problemas desde la educación, ejemplo de ello son los esfuerzos de los maestros y maestras por atender estas situaciones desde el aula que, por si fuera poco tiene su propia dinámica no resuelta, además de esto, deben considerar otros tipos de educación como son: educación ambiental, educación emocional, educación financiera, educación cívica, educación física, educación en valores, educación especial, educación sexual, educación vial, educación integral, educación empresarial, educación política, educación en al aula diversa, educación con perspectiva de género, y, ahora, educación virtual. Si bien es cierto la enseñanza no corrige necesariamente las estructuras y comportamientos, puede llegar a ser un importante motor si los ciudadanos y ciudadanas pudieran desarrollar sus capacidades de crítica y de lucha por una sociedad con mayor justicia y libre de violencia. Sin embargo, la solución a los problemas sociales siempre no lleva al mismo lugar: la educación como eterna respuesta, la carga que le imputan a 
la escuela es considerable y la mayoría de las veces necesita la participación de todos los actores sociales. ¿Por qué siempre se exige a la educación resolver todas las dolencias que aquejan a la sociedad?

Tal vez, como pone en relieve Han (2016) "En una sociedad del cansancio con sujetos del rendimiento aislados de sí mismos, también se atrofia por completo la valentía. Se hace imposible una acción común, un nosotros" (p. 67). La educación política actual carece de esa valentía, se desarrolla por completo en el rendimiento orientado a la productividad. Este nuevo orden social, atrofia por completo la idea de protesta, pues esta última surge por el deseo común de otra forma de vida, de un mundo más justo. Sin esta autorreflexión de la vida escolar "la espontaneidad de la esperanza, el arte de tomar una postura, la experiencia de la relevancia o de la indiferencia y, sobre todo, la respuesta al sufrimiento y a la opresión, el deseo de una autonomía madura, el deseo de la emancipación y la felicidad del descubrimiento de la identidad propia, todos éstos son abandonados por el interés" [de la racionalidad] (Habermas, 1973). Es en este escenario, cuando la escuela ha fracasado en su objetivo trasformar los ideales en acción social, disminuyendo todo debate y postura, generando así la indiferencia y apatía ante los problemas sociales y educativos que enfrenta el país.

Finalmente, la educación superior debe volver a sus orígenes de formar estudiantes con un pensamiento crítico reflexivo, que, en un momento dado, deberán enfrentar los problemas políticos, económicos y sociales (reales) pero, sobre todo, aprender a ser ciudadanos, la formación va más allá de sólo manejar conceptos, significa aprender a ser un ser humano capaz de amar y de imaginar "no se trata de una corrección política sino del cultivo de la humanidad" (Nussbaum, 2001 p. 35). Luchar por los derechos, exigencias y reconocimiento en todos los ámbitos siempre es arriesgarse. Es imposible escapar de su lógica. No hay ya caminos seguros, sólo posibilidades.

En tiempos donde el futuro se encuentra suspendido y para otros cancelado. No puedo dejar de pensar en la situación actual de fragmentación y aislamiento social, pero sobre todo en medio de tantas violencias, no solo del golpe del virus, sino del golpe en la economía en los países pobres. Ante este desastre social y natural, la escuela está librando otra batalla, la imposición de la tecnología hacia nuestras prácticas educativas, con el peligro que conlleva la sustitución del profesor/a y la eliminación de la escuela como espacio público, donde no sólo intervienen la enseñanza y el aprendizaje, sino que esta mediada por otras subjetividades de amistad, compañerismo, noviazgo, reforzamiento de valores, diferencias ideológicas, tolerancia etc. Aspectos que en la virtualidad son imposibles de cultivarse ante eso "Es posible que quien quiera transformar sólo pueda hacerlo en la medida en que convierta esta misma impotencia, junto con su propia impotencia, en un momento de lo que piensa y quizá también de lo que hace" (Adorno, 1998: 127)

\section{REFERENCIAS}

Adorno, T. W. (1998). Educación para la emancipación. Madrid: Morata .

Foucault, M. (1992). Vigilar y Castigar: Nacimiento de la prisión. Madrid: Siglo XX.

Instituto Nacional de Estadística y Geografía, (20 de Abril de 2020). Encuesta Nacional sobre disponibilidad y Uso de Tecnologías de la información en los Hogares. Obtenido de INEGI: https://www.inegi.org. $\mathrm{mx} /$ programas/dutih/2019/ 
Instituto Nacional de Estadísitca y Geografía, (20 de Abril de 2020). Tecnologías de la información y comunicación. En Hogares. Obtenido de INEGI: https://www.inegi.org.mx/temas/ticshogares

Giroux, H. (1992). Teoría y resistencia en la educación. México: Silgo XXI.

Gramsci, A. (1971). Cuadernos de la cárcel. Puebla: Era.

Han, B.-C. (2013). La sociedad de la transparencia. Barcelona : Herder.

Ilich, I. (2011). La sociedad desescolarizada. Buenos Aires: Godot .

Marsiske, R. (2001). La universidad de México. Un recorrido histórico de la época colonial al presente. México: Porrúa .

Nussbaum, M. (2001). El cultivo de la humanidad una defensa clásica de la reforma en la educación liberal. Barcelona : Andrés Bello .

Plá, S. (10 de Abril de 2020). La escuela en tiempo de pandemia . La jornada , págs. 6-8.

Rancière, J. (1987). El maestro ignorante. Barcelona : Laertes.

Rodríguez, M. Á. (9 de Septiembre de 2020). Televisión y educación bancaria. Obtenido de Periodico Digital E-Consulta: www.e-consulta.com/opinion/2020-08-05/television-y-educacion-bancaria Schaff, A. (1974). Historia y Verdad. México: Grijalbo . 